Nova Southeastern University NSUWorks

\title{
Comments on "Patterns of Alcoholism over Four Years"; and a Response
}

Dan E. Beauchamp

University of North Carolina at Chapel Hill

Raymon M. Costello

University of Texas Health Science - San Antonio

Rudolf H. Moos

Stanford University

John W. Finney

Stanford University

Peter E. Nathan

Rutgers University - New Brunswick/Piscataway

See next page for additional authors

Follow this and additional works at: https://nsuworks.nova.edu/cps_facarticles

Part of the Psychology Commons

This Article has supplementary content. View the full record on NSUWorks here: https://nsuworks.nova.edu/cps_facarticles/821

\section{NSUWorks Citation}

Beauchamp, D. E., Costello, R. M., Moos, R. H., Finney, J. W., Nathan, P. E., Hay, W. M., Ogborne, A. C., Pattison, E. M., Sobell, M. B., Sobell, L. C., Topper, M. D., Polich, J. M., Armor, D. J., Braiker, H. B. (1980). Comments on "Patterns of Alcoholism over Four Years"; and a Response. Journal of Studies on Alcohol, 41(7), 760-796.

Available at: https://nsuworks.nova.edu/cps_facarticles/821 


\section{Authors}

Dan E. Beauchamp, University of North Carolina at Chapel Hill

Raymon M. Costello, University of Texas Health Science - San Antonio

Rudolf H. Moos, Stanford University

John W. Finney, Stanford University

Peter E. Nathan, Rutgers University - New Brunswick/Piscataway

William M. Hay, Rutgers University - New Brunswick/Piscataway

Alan C. Ogborne

E. Mansell Pattison, Medical College of Georgia

Mark B. Sobell, Nova Southeastern University, sobellm@nova.edu

Linda C. Sobell, Nova Southeastern University, sobelll@nova.edu

Martin D. Topper

J. Michael Polich, The Rand Corporation

David J. Armor, The Rand Corporation

Harriet B. Braiker, The Rand Corporation 


\section{COMMENTS}

\section{Comments on "Patterns of Alcoholism over Four Years"; and a Response}

Dan E. Beauchamp ${ }^{1}$

There has been considerable press attention to the recent report (1) of the Rand group evaluating treatment of alcoholics in Alcoholism Treatment Centers (ATC). Once again, this attention has centered on the question of abstinence as the therapy of choice. This is unfortunate because the first and second Rand studies $(1,2)$, taken together, provide a fascinating if sobering glimpse into the impact of a major segment of our public treatment system. Depending on how you look at it, the news is either good or not so good.

The encouraging and optimistic view is this. At least $46 \%$ of all who were followed up at 4 years had experienced long periods of abstinence ( 6 months or more) or were drinking without problems. This finding represents a decline from the 18-month study, but the decline results entirely from treating as in relapse those abstaining at the 4-year point who had been abstinent for fewer than 6 months. If this group of "shortterm abstainers" had been treated as in remission, the findings of the second study would have paralleled those of the 18-month study, and roughly $63 \%$ would have been classified as in remission. Interestingly, fewer than $10 \%$ of the sample continued to drink with problems for the entire 4-year period. However, 20\% spent the greater part of the 4 years drinking with problems.

The bleaker side comes from looking at these data another way. Only $7 \%$ of the sample achieved long-term permanent abstinence. Thirteen per cent were abstinent for most of the 4 -year period. These results should serve to caution those who believe that permanent abstinence has been vindicated by the Rand group. Only $28 \%$ of the sample achieved either stable abstinence (defined as being abstinent for at least 6 months at both the 18-month and 4-year points) or were stable nonproblem drinkers at follow-up or a combination of these two outcomes. If the criterion for stability of remission is restricted even further, and includes

1 Department of Health Administration, School of Public Health, University of North Carolina at Chapel Hill, Chapel Hill, North Carolina 27514. 
only those who abstained or drank without problems (or some combination of the two) for the entire 4 years, then only $19 \%$ achieved stable remission. Thus, $81 \%$ of the sample experienced relapse during the 4 -year period.

In summary, if one examines the sample for 30 days before the 4-year point, roughly $63 \%$ are in remission, meaning that they have abstained or drunk without problems for at least 30 days. If the short-term abstainers are removed, and the time frame becomes the 6 months before the 4 -year point, the number in remission falls to $46 \%$. If the time interval is the 6 months prior to the 4-year and 18-month points, the number in remission falls to $26 \%$. And if you use the entire period of 4 years, the remission rate declines to $19 \%$.

What is absent in this study is some baseline for comparison. Until we know what happens over a 4-year period to a comparison group of untreated alcoholics who are like those who undergo treatment in the ATCS, we will not know with precision how much a difference the treatment intervention achieves. The Rand researchers found that treatment itself is less correlated with remission than are such factors as age, marital and employment status and alcohol dependency, and that the social adjustment of the sample (employment and so forth) is only marginally improved at the end of 4 years. On the question of abstinence versus nonproblem drinking, the second study does suggest that older persons who have shown signs of dependence, and who maintain a period of stable abstinence, have lower relapse rates than do those who seek stable nonproblem drinking. But the findings are not terribly impressive, and the fact remains that a significant fraction of the sample continues a rather stable adjustment with nonproblem drinking, even if some of them still drink rather heavily.

The accumulating evidence over the past decade or so indicates that drinking behavior is enormously changeable over time for all groups; the rule is flux, instability and a waxing and waning of drinking status. The work of the Rand group suggests that the same may be more or less true for alcoholism. The condition of alcoholism, at least for those who seek treatment in the ATCS, is a constant cycling between episodes of alcoholism, short-term and long-term abstinence, and nonproblem drinking.

We need to know more about the factors influencing change in all drinking behavior, including alcoholism. This is purely speculative, but there seem to be systematic forces in the social environment of all drinkers for restoring deviant drinking to a nonproblem status (forces for natural remission?), and these forces operate, perhaps with less force, for those who enter the ATCS. Thus, the ATC treatment system is one more social control system seeking to restore drinking behavior to a nonproblem status, whether this is abstinence or nonproblem drinking. Treatment seems to work best when the natural remission rate is high, and when the treatment goals are consistent with the typical sequelae of naturally occurring pressures. 
What are we to make of all of this? I think that these studies along with others will force us to view the impact of our treatment system with more realism, sophistication and even sympathy. While the justification for treatment ought never be based solely on dramatic and effective outcomes, a treatment system in which one finds nearly $50 \%$ remission rates for a cohort 4 years after entry cannot be written off as a failure even after noting all the necessary qualifications. The results we see here are not terribly different for many other chronic, disabling conditions where cycles of relapse and remission are the rule rather than the exception. Furthermore, for the population under study, the disabilities of low employment, divorce and poverty complicate the matter tremendously.

It may be possible to imagine a world where alcohol is freely available and yet people manage to drink without problems, but such a world is hardly one that we can realistically expect to live in. Alcohol problems are an expected and predictable consequence of the societal decision to make alcohol even minimally available. The central question is not whether we are to have alcoholism and other alcohol problems, but what level should we accept as tolerable and equitable, and what should be done about the casualties. In this time of economic instability, fiscal austerity and political retrenchment, the alcoholism constituency will necessarily close ranks and defend the treatment system against declining revenues and public support. But legislators and other political leaders need assurances that our policies are designed to address not just the casualties, but also the over-all rates and level of problems. The most effective treatment system can never fundamentally alter the level of a serious social problem in society. This is the task for prevention.

\section{REFERENCES}

1. Polich, J. M., Armor, D. J. and Bratker, H. Patterns of alcoholism over four years. J. Stud. Alcohol 41: 397-416, 1980.

2. Armor, D. J., Polich, J. M. and Stambul, H. B. Alcoholism and treatment. Prepared for the U.S. National Institute on Alcohol Abuse and Alcoholism. Santa Monica, Calif.; Rand Corp.; 1976. 
The authors of the 1980 Rand report (1) are to be complimented for the care and diligence displayed in its preparation. Information is presented in sufficient detail that readers can rearrange or collapse tables, recalculate findings and otherwise rework the data to answer many alternative questions which might be posed. It is difficult to "track" cases across tables, and to understand the idiosyncratic definitions given to particular clusters of empirical findings, but sufficient detail is given so that adjustments can be made that allow these findings to be placed into a perspective more familiar to each reader. In this regard, I would like to give special attention to the outcome findings as they might be compared with those that have been reported by other investigators over a long time span, 1951-1975, and in many countries. To do so, reference is made to published work with which I am most familiar.

\section{Rand Success Rates and Previous Norms}

In 1975 I (2) reviewed 58 documents published between 1951 and 1973 for details regarding patient characteristics, treatment components and outcome statistics. An attempt was made to see whether studies with similar outcome results resembled each other with regard to subject selection or types of treatment. This work was supplemented by another review (3) which added to the pool 22 studies published between 1961 and 1975 . Various recalculations of reported data were made to render studies more comparable. The thrust of this work was the discovery that the most successful studies reported "success" rates of around $45 \%$. In contrast, the authors of the 1976 Rand report (4) found an 18-month recovery or improvement rate in the area of $67 \%$, thus throwing the validity of the document into suspicion. In 1980, however, Polich et al. reported a "definitional" change and longer follow-up information which normalize the findings. Basically, their short-abstinence ( $1-5$ months) group at 18 months was discovered to be highly unstable and variable over time, and the authors concluded that "it would be inappropriate to regard short-term abstention as a form of remission" (1, p. 172).

I recalculated the 18-month outcome findings (1, Table 7.1, p. 140) in the same way as in the two reviews $(2,3)$. The 6-month abstainers $(N=115)$ and the "drinking, no symptoms" $(N=85)$ groups were added together and labeled the "success" group $(N=200)$; the other 274 were labeled the "problem" group; 62 had died and 57 of the original group of 593 (1, Table 23, p. 19) selected randomly for interview were

1 Department of Psychiatry, University of Texas Health Science Center, 7703 Floyd Curl Drive, San Antonio, Texas 78284. 
lost or unlocatable. Thus, the 18-month outcome profile reads as follows: success $=34 \%$, problem $=46 \%$, dead $=10 \%$, lost $=10 \%$. Chi-squared comparisons with outcome patterns reported by Costello et al. (3) were all statistically significant, suggesting a nonmatch. This is partly due to the excellence of the follow-up locatability rate, and the thoroughness of the mortality search which resulted in a very high death rate compared with other published reports. The "success" rate of $34 \%$ matches exactly with that of the outcome cluster labeled "good," the second most-favorable cluster (3).

Thus, in terms of previous norms, the findings seem to make sense. The Alcoholism Treatment Centers (ATC) were publicly funded programs with a preponderance of socially unstable patients. A finding that two of every three demonstrated recoveries on the basis of the limited treatment supplied seemed ludicrous. A success rate of one of three, not spectacular but still good, is much more believable. Incidentally, a spot check (5) on outcome performance at an early stage of development of the outpatient component of one of the eight centers contributing data for the Rand report suggested a success rate of $24 \%$, while that center's intermediate-care component produced a success rate of $33 \%$.

The recalculated 4-year outcome profile reads as follows: success $=$ $42 \%$, problem $=38 \%$, dead $=13 \%$, lost $=7 \%$. This is actually a remarkable finding, as it is more common to find success rates eroding over time, although perhaps not to statistically significant degrees $(6,7)$. Polich et al. report correctly that aggregate stability was discovered between the 18- and 48-month follow-ups. Yet, although an 8\% difference may not be large statistically, it is nonetheless substantial clinically and administratively, and it is in a positive direction. Thus, the apparent aggregate therapeutic gain across 18-48 months warrants more discussion despite the lack of statistical significance.

\section{Follow-up Lags}

It has long been established that a 3-month follow-up is not acceptable for program evaluation purposes (8). Polich et al. ( $1, p .183)$ suggested that a 6-month lag is also not acceptable, but that an 18-month lag produces data sufficiently reliable to allow an extrapolation to 48 months. Our own work (9) suggested that a 12-month lag allows an extrapolation to 24 months, with a stability quotient of $70 \%$ calculated on a multivariate outcome assessment instrument.

It cannot be overemphasized that a pool of treated subjects is in flux and highly unstable for a period of at least 6 months following treatment (perhaps 12 months following admission as it is frequently not clear when formal treatment is terminated) and during that time is subject to many influences which exert partial control over outcome. One of these influences, of course, is programmatic attention administered in an aftercare modality (10). 


\section{Does Treatment Work?}

This point leads to a consideration of an issue about which the authors of the 1980 report could not be definite. Although recoveries were noted, some of which were highly stable, and although modest correlations between reductions in alcohol consumption and alcohol-related problems and some forms of treatment were discovered, "Can some or all of this reduction be attributed to the intervention of treatment?" $(1, p .177)$.

No amount of statistical mumbo jumbo can answer this question for data collected in a naturalistic, free-selection setting such as described in the report, or in any other such setting when considered in isolation. Across studies, however, statistical redundancies might be interpreted as having "causal" significance. The Rand authors suggested that their data were "consistent with a small but positive effect of treatment, but other interpretations are also possible" (1, p. 178). They also reported modest correlations between outcome and measures of social stability (p. 113)-certainly not unexpected. A crude formula, ${ }^{2}$ based on accumulated empirical evidence, can be used to predict the contribution of the social stability of the clients to a program's success rate. This formula is, 0.6 ( $\left.\frac{\% \text { married }+\% \text { employed }}{2}\right)+2.3$. Therefore, from the 1980 report (1, p. 217), the predicted 18-month success rate is, $0.6\left(\frac{40+40}{2}\right)+$ $2.3=26.3 \%$. The actual rate of success was estimated to be $34 \%$ at 18 months and $42 \%$ at 48 months. Thus, this calculation suggests that 7 to $8 \%$ of the 18 -month recoveries and perhaps 15 to $16 \%$ of the 48 -month recoveries could be attributable to therapeutic intervention. Further, if the inpatient-outpatient combined treatment can be considered evidence of a functional aftercare component, then based on accumulated findings ${ }^{2}$ it might be predicted that an additional $8.2 \%$ of the cases would be found with successful adjustments as a result of the aftercare. Thus, the $34.5 \%$ predicted success rate matches closely the 18-month success rate of $34 \%$, which can be decomposed statistically in a systematic manner. That is, the social stability of the clients treated could account for $24 \%$, the aftercare efforts could account for $8.2 \%$ and a constant accounts for $2.3 \%$.

\section{Evaluation with Inappropriate Standards}

Polich et al. state that treatment effects were just barely noticeable for "either high amounts of outpatient treatment alone, or high amounts of outpatient follow-up treatment after inpatient treatment" $(1, p .178)$. Unfortunately, they proceed to suggest in the "Implications for Policy and Research" section that because "No general advantage was demon-

2 Costello, R. M. Alcoholism treatment effectiveness; slicing the outcome variance pie. Presented at the conference on Alcoholism Treatment; Finding New Directions, London, April 1979. 
strated for either setting of treatment . . . other things being equal, it may be feasible to substitute less costly outpatient treatments for more costly inpatient regimens. ... . [T] he cost-effectiveness of inpatient treatments is very much an open question" ( $p$. 182). I suggest that the authors should remain mute on the question of the effectiveness of inpatient treatments.

It can be argued that, on the basis of cumulative findings $(2,3){ }^{2}$ the long-term adjustment of alcoholics, in the aggregate, is not influenced by medical care delivered in the ordinary hospital setting, but that hospital settings could be reorganized (if the money were available) into "communities" which have long-term therapeutic impact. On the basis of evidence in the published literature, no effect on long-term adjustment should have been expected for the hospital or intermediate settings unless those settings were designed and functioned in a specialized way. My guess is that the inpatient treatment delivered in the early 1970s was not expert in this sense.

Further, to evaluate hospital care with reference to long-term adjustment is to use an inappropriate standard (11). Type II errors of statistical inference, claiming no effectiveness inappropriately, are highly probable. Rather, inpatient programs should be evaluated with a standard of performance constructed to reflect what they are designed to accomplish, that is, the "diagnosis and/or treatment of medical and/or psychiatric illnesses derived from or associated with alcohol abuse and/or alcoholism" (11, p. 41). My contention is that inpatient programs should be evaluated (with equal weight given to each of these objectives) on (a) accuracy of medical/psychiatric symptom description or diagnosis; (b) speed with which acute symptomatology is brought under control; and $(c)$ effectiveness of referral to appropriate modalities of longer-term care (12). None of these questions was addressed in the 1980 report. My opinion is that if hospital settings were reorganized and directed to long-term adjustment, the incremental effect (after the effect attributable to patient characteristics was removed statistically) would be something near $4.5 \% .^{2}$ The cost of hospital care will probably be prohibitive if only a $4.5 \%$ gain in success rate can be expected upon reorganization of inpatient programs, further reinforcing the notion that hospital programs should be designed and evaluated strictly on a short-term medical model (11). The residential, intermediate-care programs, however, are much less costly and can be designed creatively to contribute to long-term outcome. This area warrants much more investigation than it was given by Polich et al.

\section{Heterogeneity of Treatment Groups}

Polich et al. stress repeatedly the observation that "change is the dominant pattern of alcoholic behavior over time" $(p . i x)$, and conclude that alcoholism is a chronic unstable condition. Yet, despite tremendous system "noise," they were able to isolate important "signals" which warrant comment. Cross-classification of 18- and 48-month outcome 
statuses resulted in 16 possible outcome categories ( $p .154)$. Three of these categories could be considered stable and are readily recognizable to anyone who works directly in alcoholism treatment programs: (a) stable long-term abstainers, (b) stable nonsymptomatic drinkers and (c) stable symptomatic alcohol-dependent drinkers. It is important that the stable abstainers and the symptomatic drinkers seem to be sampled from the same population (with regard to many measured characteristics), but the stable nonsymptomatic drinkers differed from all other groups in several respects. In terms of drinking style on admission, fewer nonsymptomatic drinkers were in the very heavy drinking category; their number of alcohol-related symptoms was lower; they were somewhat younger, showed less unemployment, and reported having had less previous treatment for alcoholism ( $p .157)$. More interestingly, they rejected classical attitudes about alcoholism. They rejected the idea that "alcoholism is an irreversible progressive disease from which an individual can never completely recover" ( $p$. 82) and that total abstinence is the only acceptable alternative to abusive drinking ( $p .82)$; they claimed that they had not been and were not now alcoholics ( $p .83$ ) and that they could control their drinking, could avoid harm from future drinking and would not die from drinking ( $p p .83-84)$. At both 18 and 48 months they reflected a physical, social and psychological adjustment pattern as favorable as that of the long-term abstainers (p. 157). The preponderance of accumulating evidence, reported by these and by other clinical investigators, is beginning to force the conclusion that there are alternative modes of satisfactory posttreatment adjustment discoverable for persons treated in programs presumed to be reserved for "alcoholics." Although Polich et al. claim that "there are alternative modes of remission from alcoholism" ( $p .184)$, this conclusion seems to presuppose a valid diagnosis of alcoholism in all cases treated in alcoholism programs. I have learned that some $16 \%$ of the persons treated in the "alcoholic" treatment program ${ }^{3}$ with which I am involved may not be "alcoholics." Similarly to Polich et al., I reported (13) that these people are younger when first admitted for psychiatric or alcoholism treatment, younger on current admission, obtain much lower scores on alcoholism severity indicators, and are test "misses" on objective inventory screening. Thus, it seems much sounder to conclude that misdiagnosis is possible, but that the question of styles of remission from alcoholism is still an open one.

With regard to future study of the question of possible styles of remission from alcoholism, alcohol dependency seems to be a crucial concept (14). For those persons who do not qualify for the diagnosis of alcohol dependency, careful study with abstinent and drinking outcome goals seems necessary from an ethical perspective. Treatment (such as is predominant in the United States, if not worldwide) which demands

3 Alcohol Treatment Unit, Audie Murphy Veterans Administration Hospital, San Antonio. 
that people accept an ideology requiring a pathologized transformation of their personal identities (from nonalcoholic to alcoholic) without adequate testing of that necessity is mistreatment. As clinicians, we must strive to treat alcoholics as well as we can, but we cannot mistreat nonalcoholics in the process. An iatrogenic source of failure in treatment must be recognized and prevented.

On the other hand, for those persons who do qualify for the diagnosis of alcohol dependency, careful assessment of the possibility of a "drinking" style of remission is useful (and perhaps necessary) from a practical, rather than an ethical, need. Although "dependent" alcoholics may be quite in need of abstinence, they are very likely not to obtain or sustain it (only 7\% over 48 months according to Polich et al.). To insist on such a goal for each and every case is the obviously correct and safest way to proceed, but it is a sure guarantee that "professionals" (or those not committed to the faith of Alcoholics Anonymous) will have little to contribute if pursued vigorously by those having control over programs and funds. Such an assessment, however, should be reserved for those in a position able to conduct it with clinical safety and scientific credibility. It cannot be a blanket recommendation for implementation in the field.

\section{REFERENCES}

1. Polich, J. M., Armor, D. J. and Braiker, H. B. The course of alcoholism; four years after treatment. Prepared for the U.S. National Institute on Alcohol Abuse and Alcoholism. Santa Monica, Calif.; Rand Corp.; 1980.

2. Costello, R. M. Alcoholism treatment and evaluation; in search of methods. Int. J. Addict. 10: 251-275, 1975.

3. Costello, R. M., Biever, P. and Balllargeon, J. G. Alcoholism treatment programming; historical trends and modern approaches. Alcsm, Clin. Exp. Res. 1: 311-318, 1977.

4. Armor, D. J., Polich, J. M. and Stambul, H. B. Alcoholism and treatment. Prepared for the U.S. National Institute on Alcohol Abuse and Alcoholism. Santa Monïca, Calif.; Rand Corp.; 1976.

5. Costello, R. M., Giffen, M. B., Schneider, S. L., Edgington, P. W. and Manders, K. R. Comprehensive alcohol treatment planning, implementation, and evaluation. Int. J. Addict. 11: 553-570, 1976.

6. Fitzgerald, B. J., Pasewark, R. A. and Clark, R. Four-year follow-up of alcoholics treated at a rural state hospital. Q. J. Stud. Alcohol 32: 636-642, 1971.

7. Gerard, D. L. and Saenger, G. Interval between intake and follow-up as a factor in the evaluation of patients with a drinking problem. Q. J. Stud. Alcohol 20: 620-630, 1959.

8. Charnoff, S. M., Kissin, B. and Reed, J. I. An evaluation of various psychotherapeutic agents in the long-term treatment of chronic alcoholism; results of a double blind study. Am. J. Med. Sci. 246: 172-179, 1963.

9. Costello, R. M., Baillargeon, J. G., Biever, P. and Bennett, R. Secondyear alcoholism treatment outcome evaluation with a focus on MexicanAmerican patients. Am. J. Drug \& Alcohol Abuse 6: 97-108, 1979. 
10. Costello, R. M. Alcoholism aftercare and outcome; cross-lagged panel and path analyses. Br. J. Addict. 75: 49-53, 1980.

11. Joint Commission on Accreditation of Hospitals. Accreditation manual for alcoholism programs. Prepared by the Accreditation Council for Psychiatric Facilities of the Joint Commission. Chicago; 1974.

12. Costello, R. M. Evaluation of treatment programs. In: Pattison, E. M. and Kaufman, E., eds. American handbook of alcoholism. New York; Gardner. [In press.]

13. Costello, R. M. and Baillargeon, J. G. Alcoholism screening inventory; replication of Reich and extension. Br. J. Addict. 73: 399-406, 1978.

14. EDwards, G. The alcohol dependence syndrome; usefulness of an idea. Pp. 136156. In: Edwards, G. and Grant, M., eds. Alcoholism; new knowledge and new responses. London; Croom Helm; 1977.

\section{Rudolf H. Moos and John W. Finney ${ }^{1}$}

Cronbach (1) has observed that evaluations of intervention programs -especially programs that seek to alleviate chronic conditions which have proven resistant to change efforts-are likely to make only a passing contribution unless they add to our understanding of the basic problem. In their incisive report on the 18-month and 4-year follow-ups of a random sample of 922 men who contacted or were admitted to an Alcoholism Treatment Center (ATC), Polich et al. (2) have adopted this exacting standard. Since the primary data are derived from a naturalistic study of patients from a heterogeneous set of 8 public facilities, they provide a rich source of information about the course of alcoholism.

In this commentary, we focus on three major areas: posttreatment drinking status and psychosocial functioning, nonproblem drinking versus abstinence, and the effects of treatment. Our interpretation of the findings is somewhat more optimistic than that of the Rand researchers. More important, we believe that the findings highlight the need for a "paradigm shift" in evaluation research to focus more attention on the process of treatment and the role of posttreatment factors in the course of alcoholism.

1 The Social Ecology Laboratory, Department of Psychiatry and Behavioral Sciences, Veterans Administration, and Stanford University Medical Center, Palo Alto, California 94305.

ACKNOWLEDGMENTS.-Preparation of this commentary was supported in part by NIAAA Grant AA02863 and Veterans Administration Medical Research Funds. We thank Ruth Cronkite for her comments on an earlier draft of the manuscript. 


\section{Posttreatment Drinking Status and Psychosocial Functioning}

Four-Year Status and Change. By revealing the variability of posttreatment functioning, the results underscore both the severity and chronicity of alcoholism and the potential for long-term remission and even "recovery." The fact that $14.5 \%$ of the 781 successfully followed men had died ( $2 \frac{1 \%}{2}$ times the number expected), many from alcohol-related causes, is a harsh reminder of the seriousness of alcoholism, as is the fact that $54 \%$ of the men remaining alive were drinking heavily and had recently experienced at least 1 serious symptom or consequence of drinking at the 4-year follow-up. On the other hand, there are hopeful signs: a group of $28 \%$ of the men had abstained for at least 6 months (the majority for 1 year) and 18\% were drinking limited amounts and suffering no serious symptoms or consequences. In addition, the death rate for long-term abstainers was no higher than that expected in the general population. Since $90 \%$ of the men were serious alcohol abusers 4 years earlier, this represents dramatic improvement for a substantial portion of the sample.

With respect to social adjustment at the 4-year follow-up, Polich et al. found that $55 \%$ of the surviving patients were unmarried (36\% divorced), $5 \%$ were living in group quarters, $48 \%$ were unemployed and $60 \%$ were earning less than $\$ 500$ per month. The authors note some positive change over time, but they conclude that there was little or no improvement in social adjustment. However, the data can be viewed in a more favorable light by incorporating the notion of "relative improvement" that was used in the discussion of social adjustment in the 1976 report (3). While the relative improvement shown over 4 years is negligible on marital status, it is 30\% on employed status, 33\% on earning over $\$ 500$ per month, and $62 \%$ on not living in group quarters. Furthermore, the social improvement of patients who were not experiencing drinking problems may have been offset by the social decline of those who developed dependence symptoms or adverse consequences from drinking.

Comparison of Patient Psychosocial Functioning with General Population Norms. Polich and his colleagues also compared patient psychosocial functioning against an absolute standard--"general population" norms. They found that the patient sample as a whole exhibited a substantially lower level of psychosocial functioning at the 4-year follow-up in comparison with different "general populations," and that even patients in remission at 4 years had psychosocial deficits. Since the "general populations" used for comparison are not entirely appropriate, these results present an overly pessimistic picture of patients' psychosocial functioning. For the psychiatric symptoms, a sample of younger residents from a relatively affluent city (Seattle) was used. For psychological trait measures, comparison data were drawn from Canadian enlisted military personnel. Finally, for the social adjustment variables, general population (1970 Census) data were used, but, as the authors acknowledge, some of the difference found between this population and the ATC sample 
may be due to socioeconomic differences that are not the result of a history of alcoholism among the patients.

Two recent studies $(4,5)$ comparing "recovered" alcoholics with sociodemographically matched community controls found greater similarity between groups on a variety of measures (social activity was an exception in which differences remained). The more positive prognosis for recovered alcoholics shown in these studies may be due to two other features (in addition to sociodemographic matching) that contrast with the Rand research. One is that persons who were "stable" in remission status for a period of 2 years or more were examined, in contrast to the primary Rand focus on drinking status in the 6-month "window" prior to the 4-year follow-up. The second distinctive feature is that the two samples overrepresent "high bottom" alcoholics, while the Rand sample contains more "low bottom" alcoholics. Since high-bottom alcoholics are less likely to experience deterioration in social-psychological domains, it is not surprising that they have few psychosocial deficits in a cross-sectional analysis at follow-up. Low-bottom alcoholics, on the other hand, have few resources on which to base and sustain social-psychological rehabilitation, even if abstinent. Subgroups of alcoholic patients show varied patterns of psychosocial adjustment following treatment, but at least some patients can attain levels of psychosocial functioning comparable with those of their nonalcoholic counterparts in the community.

\section{Nonproblem Drinking and Abstinence}

One specific aspect of posttreatment drinking behavior is the source of considerable controversy: "moderate" or "nonproblem" drinking. Scattered throughout the 1980 report are important findings on two questions that are at the heart of the moderate drinking debate: (1) What characteristics differentiate moderate or nonproblem drinkers from abstainers? and (2) How "successful" are persons adopting each approach after treatment for alcoholism?

In general, the Rand findings on distinguishing characteristics of "stable" nonsymptomatic drinkers and abstainers are consistent with the results of previous studies, most of which have focused on persons who remained abstinent or maintained nonproblem drinking patterns for only a short time (such as 6 months) after treatment. Of particular note is the consistency with which "successful" nonproblem drinkers have less severe prior drinking behavior and symptoms than abstainers (e.g., 6). This finding obtains whether treatment has been oriented toward abstinence or moderate drinking.

"Success" Criteria and Posttreatment Factors. Two types of information are presented regarding the "success" of nonproblem drinkers and abstainers: $(a)$ outcome on psychosocial dimensions, and $(b)$ relapse into heavy drinking. Outcome on psychosocial dimensions did not differ, in general, between either the 4-year nonproblem drinkers and abstainers, or between "stable" nonsymptomatic drinkers and abstainers. 
The complexity of the relapse issue is illustrated by the Rand researchers' quandary over whether to compare the 30-month relapse rate of nonsymptomatic drinkers (22\%) with that of long-term abstainers (12\%), short-term (1-5 months) abstainers (29\%), or both. This problem might be viewed more properly in terms of equating nonsymptomatic drinkers and abstainers on the length or stability of their initial drinking or abstinence pattern. Pitting the nonproblem drinkers against the long-term abstainers involves comparing a group whose drinking behavior has been established for 1 month or more with a second group whose abstinence has been maintained for 6 months or more. The lower relapse rate among the long-term abstainers may reflect the greater stability of their initial pattern of behavior rather than the relative effectiveness of abstinence over nonproblem drinking.

So far as we know, the data on differential relapse rates presented in the Rand report are unique. Three variables-dependence symptoms at intake, age and marital status - that interacted with nonproblem drinking versus abstinent status are identified and integrated in a plausible theory of differential relapse. The speculation regarding the social pressure to drink that younger unmarried alcoholics are likely to experience, and the pressure from spouses for abstinence that married patients are likely to be exposed to, illustrates the importance of considering posttreatment factors as significant influences on drinking behavior. Given the prominence of posttreatment drinking environment variables in the Rand theory of differential relapse, and the availability of appropriate data (Questions 15 and 17 on pages $278-279$ of the 1980 report), it would be informative to explore the association between the drinking behavior of close friends and spouses or girlfriends and 4-year abstainer versus nonproblem drinker status.

Thus far, we have adopted the stance taken by the Rand researchers in much of their report-that is, we have focused on posttreatment psychosocial functioning and drinking behavior (including nonproblem drinking versus abstinence) without considering the role of treatment. However, at least two findings in these areas are suggestive of possible treatment effects. First, more improvement took place in drinking behavior (the primary focus of alcoholism treatment) than in social adjustment. Second, amount of treatment (treatment that was presumably abstinence-oriented) was related to abstinence but not to nonproblem drinking $(2$, Table 6.6, p. 119). It is appropriate then to consider in more detail the effects of ATc treatment and the analyses from which treatment effects were estimated.

\section{The Effects of Treatment}

The Rand researchers found that persons who received some ATC treatment were functioning better at the 18-month and 4-year follow-ups than were persons who only contacted an ATC. Amount of treatment, as indicated by the number of outpatient visits (less than 6 vs 6 or more), or the intensity of combined inpatient and outpatient treatment, 
was positively associated with outcome, but not when it was indexed as duration of treatment in only hospital or only intermediate-care facilities. Over-all, only $9.2 \%$ of the variance in drinking problems (dependence symptoms or adverse consequences vs no problems) at 4 years was accounted for by patient characteristics and treatment variables combined. These data were interpreted as suggesting a weak "effect" of treatment on the course of alcoholism, but it is important to note that they can also be interpreted as indicating a weak "effect" of patient background and intake symptom status on subsequent functioning.

While we would not expect ATC treatment to have a strong effect after 4 years, for reasons to be outlined, we think that its (potential) impact may be underestimated by the Rand analyses. This conclusion follows from several considerations in addition to the usual concerns about attenuation of relationships due to measurement error and dichotomization of treatment and outcome variables.

The first consideration involves the "third face of evaluation"-assessment of "treatment integrity" or treatment implementation. No data were available to the Rand researchers that would allow them to determine to what degree patients were exposed to the intended treatment. Although an ATC patient may have been hospitalized for 10 days, he may not have been actively involved in a treatment regimen. We also know nothing about the "quality" of treatment, e.g., the training and motivation of the counselors, the extent to which they established meaningful relationships with their clients, or the emphasis they placed on improving patients' posttreatment functioning in the community. Furthermore, as is pointed out in the report, what were classified as "large amounts" of treatment do not necessarily represent "clinically intensive" interventions.

Second, the "untreated" contact-only group (32\% of whom were abstainers or nonproblem drinkers at the 4-year follow-up as compared with $42 \%$ and $53 \%$ of the low and high treatment groups, respectively) eventually sought out and received almost as much "treatment" as the treated groups! In fact, when ATC and other formal treatment is considered together with Alcoholics Anonymous, only 33\% of the contactonly group were untreated. Since most of the contact-only group had been in treatment, the Rand researchers are comparing three treated groups (rather than an untreated group and two treated groups), and thus probably are underestimating the effects of treatment. Prospective patients cannot be "assigned" to untreated control groups; they actively search out the help they feel they need (7).

Third, it is possible that the over-all relationship between ATc treatment and outcome was weak because, while some patients benefited substantially, others were not helped and may even have deteriorated. Deterioration effects have been identified in 5 to $10 \%$ of different groups of treated patients (7), and we suspect that such effects occur among alcoholics as well. If treatment were implemented more adequately and patients were optimally matched with the appropriate therapeutic regimen, the over-all impact of treatment could be much stronger. 
Fourth, although the authors present a plausible rationale concerning the way in which selection (as opposed to treatment) effects might account for the positive relationship between outpatient visits and remission status, they do not consider selection processes that could explain the lack of association between inpatient treatment duration and outcome. There are reasons to expect both good and poor prognoses for patients remaining in treatment for both short and long periods. Short-term patients might include persons who are poorly motivated for treatment, as well as persons who have supportive family and work settings to return to after hospitalization. Long-term patients are likely to include individuals who are highly motivated for treatment, as well as persons who are dependent on the hospital (i.e., have nonsupportive settings to return to on release). With selection forces such as these at work, it would not be surprising to find little over-all relationship between length of stay and remission status at follow-up, even if longer stays had a positive impact.

Finally, the effects of treatment are likely to diminish over time and to depend on posttreatment factors that facilitate or inhibit them. To evaluate the probable maximum influence of treatment accurately, therefore, patients should be assessed when they terminate the "initial" treatment episode. Six hours of outpatient treatment may have strong immediate effects on a patient, but there is reason to expect that such effects are "diluted" by patients' stressful and unsupportive community settings.

These considerations lead to several conclusions: (1) methodological problems can result in underestimates as well as overestimates of treatment effects; (2) the intensity and quality of treatment must be evaluated in outcome studies and potential deterioration effects should be considered; (3) the effects of treatment are not adequately assessed by comparing formally treated groups with control groups, since the control groups may also be treated; (4) natural or "spontaneous" remission may be due in part to people receiving some help from informal community resources and thus to "treatment"; (5) the effect of the decision to enter and remain in treatment is inextricably intertwined with the effect of treatment itself; and (6) posttreatment factors can modify the influence of treatment outcome.

\section{Directions for Future Research}

The Need for a Paradigm Shift. Polich et al.'s findings that patient characteristics and treatment variables combined account for less than $10 \%$ of the variance in posttreatment drinking problems, and that the drinking behavior of many individuals is quite variable over time, point to the need for a shift from the usual intake-treatment-outcome evaluation paradigm and for consideration of the role of posttreatment factors in the course of alcoholism. The report did note that five major life events (such as death of a close friend) were not associated with 4-year follow-up status. However, this analysis considered only a handful of events as they occurred over a relatively long period. Our own research 
(e.g., 8) suggests that negative life change events as well as other posttreatment factors, such as family environment and family functioning characteristics and features of the work environment, can account for additional variance in treatment outcome.

Integrative Causal Models. A promising strategy for future research is to combine patient, treatment and posttreatment variables in integrative causal models. Using such a model, Cronkite and Moos (9) found that a substantial portion of the total causal effect of patient background on outcome was indirect or mediated by the link between patient background and posttreatment factors. For instance, patients with higher sociodemographic status were likely to return to less stressful life situations after treatment. In other words, patients' background characteristics may indicate not only what "the alcoholic brings to treatment" in terms of personal resources, but also what the patient will return to after treatment in terms of environmental resources and stressors. The model developed by Cronkite and Moos (9) also affords a more comprehensive understanding of treatment effects. Although the direct effect of treatment on outcome was weak, its total causal effect was more substantial, because of indirect effects of treatment via posttreatment factors. More specifically, treatment was linked with reduced stressors and more effective coping responses, which in turn were associated with improved individual functioning at follow-up.

Research Designs and Inferences about Treatment Effects. The Rand researchers are commendably reluctant to infer causal relationships between treatment and outcome from the results of their correlational analyses. They urge that experimental studies with random assignment of patients to treatment and control groups be conducted to provide a stronger basis for estimating treatment effects. However, there are many situations in which true experiments cannot be implemented because of ethical or practical considerations. We would like to point out that there is a "middle ground"-research designs that do not require random assignment (at least in the usual sense that each patient has an equal probability of being assigned to each treatment-control condition), but which still provide a stronger basis for inferring treatment effects than do post-hoc statistical adjustments for pretreatment patient characteristics that relate to posttreatment functioning.

Two feasible "middle ground" strategies are outlined by Reichardt (10). One is to model the process of selection into treatment-either through explicit control over selection by the researcher or through more extensive ethnographic or empirical assessment. A second is to model the growth or change that probably would occur in the absence of treatment. For example, patients' functioning can be assessed twice over an interval corresponding to the typical duration of treatment. Changes taking place during that period can be used as baselines against which to compare the effects of subsequent treatment, although it is important to obtain information about any formal or informal treatment that participants obtain during the "pretreatment" interval. 


\section{Conclusion}

Responding to increased public pressure for program evaluation and accountability, the NIAAA monitoring system and the Rand reports have established a "climate of inquiry" that offers promise for improving the treatment offered to alcoholic patients. The results of the 1980 report are hopeful in highlighting the variability in status over time and thus the malleability of alcohol abuse. When these positive signs are juxtaposed against the amount of impaired functioning and death due to alcoholism, they underscore the urgency of developing more powerful treatment regimens. We believe that the effects of treatment have not yet been evaluated adequately and that applying cost-effective forms of shortterm treatment in a blanket fashion to all patients could actually lead to higher long-term financial and social costs as inadequately treated patients relapse and are readmitted for more intensive treatment. We also feel that treatment is more likely to be effective when it is directed toward improving patients' functioning in the specific settings they will occupy following treatment. By developing research paradigms that explore treatment processes in greater detail and also focus on the posttreatment experiences of patients, we should be able to account for more than $10 \%$ of the variance in outcome and to provide information that will allow clinicians to help patients more effectively.

\section{REFERENCES}

1. Cronbach, L. J. Designing educational evaluations. Stanford, Calif.; Stanford Evaluation Consortium; 1978.

2. Polich, J. M., Armor, D. J. and Braiker, H. B. The course of alcoholism; four years after treatment. Prepared for the U.S. National Institute on Alcohol Abuse and Alcoholism. Santa Monica, Calif.; Rand Corp.; 1980.

3. Armor, D. J., Polich, J. M. and Stambul, H. B. Alcoholism and treatment. Prepared for the U.S. National Institute on Alcohol Abuse and Alcoholism. Santa Monica, Calif.; Rand Corp.; 1976.

4. Kuntines, W., Ball, L. and Wood, G. Personality characteristics of long-term recovered alcoholics; a comparative analysis. J. Consult. Clin. Psychol. 46: 971-977, 1978.

5. Moos, R. H., Finney, J. W. and Chan, D. A. The process of recovery from alcoholism. I. Comparing alcoholic patients and matched community controls. J. Stud. Alcohol. [In press.]

6. FinNey, J. W. and Moos, R. H. Characteristics and prognoses of nonproblem drinkers and abstainers. J. Stud. Alcohol. [In press.]

7. Bergin, A. E. and Lambert, M. J. The evaluation of therapeutic outcomes. Pp. 139-189. In: Garfield, S. L. and Bergin, A. E., eds. Handbook of psychotherapy and behavior change; an empirical analysis. 2d ed. New York; Wiley; 1978.

8. Finney, J. W., Moos, R. H. and Mewbonn, C. R. Posttreatment experiences and treatment outcome of alcoholic patients six months and two years after hospitalization. J. Consult. Clin. Psychol. 48: 17-29, 1980. 
9. Cronkite, R. C. and Moos, R. H. The determinants of posttreatment functioning of alcoholic patients; a conceptual framework. J. Consult. Clin. Psychol. 48: 305-316, 1980.

10. ReichardT, C. S. The statistical analysis of data from nonequivalent group designs. Pp. 147-202. In: Cook, T. D. and Campbell, D. T., eds. Quasiexperimentation; design and analysis issues for field settings. Chicago; Rand McNally; 1979.

Peter E. Nathan and William M. Hay ${ }^{1}$

"Irrationally held truths may be more harmful than reasoned errors."

Thomas Henry Huxley

(The Coming of Age of "The Origin of Species")

Depending on point of view, the following beliefs about alcoholism and its treatment can be seen as irrationally held truths or reasoned errors:

(A) The only successful alcoholism treatment outcome is abstinence. or $(B)$ Nonproblem drinking is an appropriate treatment goal for alcoholics.

(A) The kind of treatment an alcoholic receives directly determines his chances for a successful outcome. or (B) It doesn't matter what kind of treatment an alcoholic receives; if he is motivated for treatment, outcome of treatment will be successful.

(A) Alcoholics make up a unitary, homogeneous group. or (B) Alcoholism takes a variety of forms and is arrayed along a number of different dimensions.

Does the Rand report (1) on patterns of alcoholism over 4 years permit us more easily to differentiate between irrationally held truths and reasoned errors? That too depends on point of view. If you believe that the Rand report was well-designed, that its results can be believed, you will accept options (B) above as the truth because Rand data support them-although some will think you have done so irrationally. If, on the other hand, you view the Rand study as flawed, you will choose options $(A)$-although others will consider that choice a reasoned error.

1 Alcohol Behavior Research Laboratory, Rutgers University, New Brunswick, New Jersey 08903. 
Take the question of treatment goals and outcomes. Rand report data are that (1) roughly one in five patients followed through 4 years who was both alive and could be interviewed at the 4-year mark was judged to be drinking without problems; (2) nonproblem drinkers were not more likely than abstainers to relapse into problem drinking; and (3) nonproblem drinkers were not more likely than abstainers to be psychiatrically disturbed. These data suggest that nonproblem drinking was one outcome of the alcoholism treatment Polich and his colleagues studied so intensively. But do these data also recommend nonproblem drinking as an appropriate treatment goal for alcoholics? A reasoned argument linking the modest but undeniable incidence of nonproblem drinking with nonproblem drinking as a treatment goal could be made; in our judgment, though, such syllogistic reasoning might be in error, both because documented success for treatment of alcoholics with this goal has been only occasional and because a proven way to choose alcoholics who will benefit from this treatment mode has not been developed. By the same token, those who see in the Rand report support for the traditional view that abstinence is the only appropriate goal in the treatment of alcoholics may well be stating an irrationally held truth; they point to opinion, conviction and belief, but they have no empirical data to support what remains largely an open question.

Problems posed by Rand report data used to confirm or deny beliefs about treatment outcome can also be illustrated by citing one of George Bernard Shaw's most endearing characters, Lord Undershaft, Munitions King and father of Major Barbara (act 2):

Undershaft. My dear Barbara: alcohol is a very necessary article. It heals the sick-

Barbara. It does nothing of the sort.

Undershaft. Well, it assists the doctor; that is perhaps a less questionable way of putting it. It makes life bearable to millions of people who could not endure their existence if they were quite sober. It enables Parliament to do things at eleven at night that no sane person would do at eleven in the morning. . . .

The difficulties Undershaft and his daughter the Salvation Army lass have in agreeing on alcohol's place in the scheme of things are paralleled by our difficulties in evaluating the adequacy of the research on which the Rand report is based. As a start, we recall our assessment (2, pp. 318-319) of the 4-year study's 18-month predecessor (3):

"Most of the follow-up assessments were based on patients' self-reports of changes in drinking behavior and in vocational and familial adjustment. Selfreports have been criticized by many as unreliable and self-serving. Further, improvement in psychological functioning, job performance, family adjustment, and drinking behavior was not measured directly. . . . Finally, much more emphasis was placed on the significance of improvements in drinking as a measure of therapeutic efficacy than improvements in other important areas of life functioning, a decision which has been questioned. . . . But the Rand study also had important strengths. It surveyed a very large group of 
geographically and demographically diverse clients with relatively sophisticated sampling procedures designed to ensure the representativeness of the sample. It developed survey instruments which sampled a broad range of behaviors relevant to alcoholism. It followed subjects for longer than the usual follow-up interval and succeeded in reaching over 2000 of them at the 6-month mark and over 600 at 18 months. Finally, the study was designed to permit pre- and posttreatment comparisons of subjects' level of functioning in a variety of spheres. ... In short, the survey could be considered a representative model of modern survey technology."

Our reactions to the 4-year study are in many ways similar to those to the 18-month report. In our view, the 4-year Rand report is close to the state-of-the-art in survey research in terms of subject numbers, design scope, follow-up intervals, and sampling methods and procedures. Though we were quite positive about the 18 -month study, we find the 4-year study to be a considerable improvement.

For one thing, the latest report incorporates a number of very positive changes in follow-up and self-report validation procedures. Multiple collateral measures (largely absent in the 18-month study) are now used. As well, the follow-up rate has increased from $60 \%$ at 18 months to $85 \%$ at 4 years, decreasing dramatically the possibility of nonresponse bias. Lengthening the drinking assessment period from 30 days to 6 months results in reclassification of short-term abstainers in the 18-month study and a subsequent reduction in the percentage of remission from 67 to $54 \%$, likely a truer picture of the real state of things (actually, drinking was assessed over the 30 days prior to the last drink while drinkingrelated consequences were assessed over 6 months). Too, criteria for determining alcohol problems at 4 years were made more stringent. Taken together, these methodological changes strengthen the report by increasing the likelihood that its results accurately portray the world of the alcoholic as it really is.

On the other hand, the following important limitations inherent in the study's basic design remain: (1) no noncontact control group was used and insufficient data were gathered to determine whether the contactonly group was equivalent to other groups at baseline-without this additional group or these data, it is not possible to know whether improvement was a function of treatment, regression to the mean, spontaneous remission or some combination of these factors; (2) the absence of multiple samples on all measures across the 4-year follow-up period (e.g., drinking and psychosocial measures) makes their unequivocal acceptance impossible; and (3) discrepancies in operational definitions of dependent variables between the 18-month and 4-year studies make direct comparison between the two sets of data hazardous.

Moreover, the Rand study was not a randomized experiment. Instead, it relies heavily on correlational procedures. While these procedures can identify relevant hypotheses to be tested experimentally, causal relationships must not be inferred from correlational data. Over-all, the study's authors are conservative in their interpretation of data, especially of 4-year data. They are also gratifyingly open to plausible rival hypotheses. 
Yet the correlational data presented offer a particular problem when it comes to evaluating the impact of treatment on follow-up status. For example, the abstinence rate for Alcoholics Anonymous "regulars" was the highest of any group. Yet one cannot directly infer from this relationship that A.A. membership was responsible for increased rates of abstinence, even though some have done so. Perhaps, as the authors suggest, A.A. membership was simply more congenial to persons who had decided not to drink, while it was virtually impossible for others. A determination of the truth of A.A.'s effects and of the potency of nonproblem drinking outcomes must await studies with controlled experimental manipulations.

Until that day comes, though, we take a cautious but fundamentally positive view of the 4-year Rand study and its findings. In our judgment, the authors of the Rand report have provided us a basis for differentiating between reasoned truths and irrationally held errors. The rest is up to us.

\section{REFERENCES}

1. Polich, J. M., Armor, D. J. and Braiker, H. B. The course of alcoholism; four years after treatment. Prepared for the U.S. National Institute on Alcohol Abuse and Alcoholism. Santa Monica, Calif.; Rand Corp.; 1980.

2. Nathan, P. E. Behavior therapy and behavior modification in the treatment of alcoholism. Pp. 305-357. In: Mendelson, J. H. and Mello, N. K., eds. The diagnosis and treatment of alcoholism. New York; McGraw-Hill; 1979.

3. Armor, D. J., Polich, J. M. and Stambul, H. B. Alcoholism and treatment. Prepared for the U.S. National Institute on Alcohol Abuse and Alcoholism. Santa Monica, Calif.; Rand Corp.; 1976.

Alan C. Ogborne ${ }^{1}$

This latest report on alcoholism research from the Rand Corporation (1) summarizes 4 years of intensive research designed to answer basic questions about the long-term progress of problem drinkers following treatment. The results are neither unexpected nor surprising. Problem drinking is confirmed as a chronic, unstable condition; normal drinking by some erstwhile problem drinkers is again demonstrated; improvements in drinking habits are shown to be marginally correlated with changes in other life areas; problem drinkers emerge as a heterogeneous

1 Clinical Institute, Addiction Research Foundation, 33 Russell St., Toronto, Ontario M5S 2S1, Canada. 
group and their progress following treatment is shown to depend upon the severity of their initial condition. It is a sad reflection on the state of the alcoholism field that these simple truths, evident from so many other studies and observations, need to be continually reaffirmed. Only in a field populated by persons with conditioned aversion to empirical data could one generate any excitement about findings that mainly reinforce conclusions evident to rational, informed beings for the past 20 years. One can only hope that this report will finally lay to rest that moribund, yet tenacious conception of problem drinking as a manifestation of a single diseaselike entity which runs a predictable course.

The predictability of the Rand results in no way, of course, belittles the achievements of the researchers. On the contrary, the report is a prime example of the potential contribution of social science to the study of a social problem, and the authors are to be congratulated on their management, analysis and presentation of this most difficult art formthe longitudinal study. An 85\% 4-year follow-up rate is itself a testimony to good research management and initiative.

The over-all rate of improvement in the sample was low and not much different from improvement rates suggested by studies of spontaneous or natural remissions. One wonders whether the treatments given to sample members were based on an appreciation of the multisyndrome nature of problem drinking which emerges so clearly from the Rand study. Most likely they were not. Rather, as is so often the case in the alcoholism treatment field, the treatments were probably applied to all who happened to show up regardless of their needs and problems. The over-all long-term poor showing of the sample, and the absence of any significant treatment by patient interactions from the earlier follow-up reports, may well be a testimony to this anomalous feature of alcoholism delivery systems. Treatment planners would do well to read this report carefully and to take care that, in future, treatments are not based on outmoded notions of what "ought" to be done for all problem drinkers, but should follow from careful and detailed assessments of the characteristics of individuals. Preliminary results suggest that younger problem drinkers who are less dependent upon alcohol may well be appropriate for controlled drinking programs, while more traditional programs might best concentrate on older, more dependent drinkers.

The instability of outcomes in the sample studied should be of particular concern to those involved in outcome studies. Clearly, the stability of outcomes over time is far from perfect, and this raises serious doubts about the generalizability of results from many previous follow-up studies and studies of patient characteristics as predictors of treatment outcome. Future outcome studies should, therefore, include multiple outcome assessments and should be extended until such time as outcome stability can be clearly demonstrated.

The new Rand study does not, of course, add a great deal to our understanding of the dynamics of relapse and remission-a shortcoming readily acknowledged by the authors. It might, for example, have been 
useful simply to ask respondents about the conditions under which relapses or remissions tended to occur. Several smaller-scale studies have looked at this issue and have generated some interesting ideas for training patients to cope with relapse-provoking situations. Issues such as this could usefully be addressed in future longitudinal studies which, after all, potentially provide unique opportunities for unraveling the dynamics of problem drinking and its relationship with events in the natural environment.

\section{REFERENCE}

1. Polich, J. M., Armor, D. J. and Bratker, H. B. Patterns of alcoholism over four years. J. Stud. Alcohol 41: 397-416, 1980.

E. Mansell Pattison ${ }^{1}$

The second Rand report (1) has been awaited with anticipation because it provides one of the first large national samples of long-term treatment follow-up. As with the first Rand report (2), the findings are not unique, nor surprising, but are confirmatory and explicative of trends indicated in prior research. Some of the methodological problems encountered in the first report have been rectified here, although some substantive methodological issues remain, as will be noted.

Several major findings stand out. First, a very small percentage of the treatment cohort maintained continuous abstinence over 4 years (7\%), while a similar percentage maintained continuous nonproblem drinking (7\%) and another small group alternated between abstinence and nonproblem drinking (5\%). Thus only $14 \%$ of the treatment sample maintained one mode of successful outcome, and $19 \%$ of the sample maintained continuous successful outcome in terms of drinking behavior per se. From another perspective, using a 6-month prior assessment period, at the 4-year mark there was a $46 \%$ current success rate, compared with a 67\% success rate in the first Rand report. These data reflect the differences between continuous success rates and success rates at a given point in time, while the differences between the second and the first report indicate the significance of the use of more stringent criteria in the definition of successful outcome. I concur with the use of the more

1 Department of Psychiatry and Health Behavior, Medical College of Georgia, Augusta, Georgia 30912. 
stringent criteria, but in turn there is a potential distortion of the definition of "successful" treatment. I shall return to this issue later.

Second, over-all, the abstinent and nonproblem drinking groups are relatively similar, which suggests that these are two similar successful drinking outcome criteria. This finding may well undergird further clinical efforts to develop nonproblem drinking treatment programs, although the cautions of the authors about greater vulnerability to relapse in the nonproblem drinking group should be carefully heeded.

Third, the report clearly documents the major increase in mortality among alcoholics compared with the general population, because of both the direct and indirect effects of alcohol. This underscores the necessity to account for mortality cases in follow-up cohorts, which can skew follow-up statistics. Further, it underscores the clinical importance of paying attention to the medical complications of alcoholism, as well as the psychological consequences revealed in the higher suicide rates.

Fourth, the report clearly indicates the instability of drinking behavior over a 4-year period. This is not a surprising finding, but the report certainly emphasizes it. Obviously, we cannot be content with 6- or 18-month data to assess treatment. As with research on the treatment of cancer, we had best consider 5-year follow-up samples.

Yet, the report does not have the data to indicate what the critical variables may be that influence changes in drinking behavior over this 4-year period. The rough indices of marriage, age and high-low dependence $(3$, Table 7$)$ are merely suggestive. We could speculate on how these variables and others might influence drinking behavior. But that is only speculation. Thus the report highlights the need for intensive and comprehensive long-term follow-up studies to elucidate critical variables, much as we have had interactive studies of drinking behavior in situ over the last decade. Such intensive studies cannot be intermittent surveys of large populations, but will require personal and frequent contact and the collection of intimate and detailed life behavior.

Fifth, the report finds much less improvement in the social parameters of rehabilitation. This again is not surprising, given the poor social status of the sample at entry. I am disappointed that the authors did not pursue this area in further detail. For example, we need to know whether the abstainers and nonproblem drinkers demonstrated social improvement or not; whether they differ; and whether they differ from the problem drinking group. Further, we need to know whether there were correlations between sociodemographic and economic variables at entry with drinking status at both 18 months and 4 years.

The observation that changes in drinking behavior are not highly correlated with other parameters of life rehabilitation is not new, as has been documented elsewhere (4). In fact, research has moved beyond that observation, to determine via path analysis the predictive contribution of such preexistent social parameters to treatment outcome (5-7). Thus, if the authors have such data available in their files, it would be most desirable to publish such statistical analyses. 
I find the above conclusions of the report not controversial, since they are congruent with available published research.

Now I should like to turn to several methodological problems, which do not undermine the substance of the findings, but do limit their generalizability. First, we must consider the sample of alcoholics on which the study is based. The authors state that the cohort "displayed many aspects of impairment and social maladjustment that are typical of most alcoholic samples" (3, p. 399). I agree that this severely impaired sample is typical of many alcoholics, but certainly not of all alcoholics. And therefore, this is not a study of typical alcoholics. For example, in my and my colleagues' own research $(8,9)$ we demonstrated major differences in educational, family, vocational, psychological and medical status of different alcoholic subsamples. In our aversion-hospital and outpatient samples, the social integration and social stability of the samples were much higher than in the sample in the Rand 1980 report. Conversely, our prison sample had even poorer social integration and stability than the Rand sample. Our first two groups had different patterns of social rehabilitation and abstinence or nonproblem drinking, with more stability than the Rand 1980 sample, with even poorer prognosis and greater drinking instability in the prison population. In fact, the Rand data look much like those of another population in our studies-the halfway-house group.

Now Polich et al. suggest that "the risk of nonproblem drinking varies substantially between different subgroups of alcoholics" $(3, p$. 414). I concur with their conclusion, but suggest that their study sample is a biased sample to investigate this proposition. Their cohort is already a socially unstable population with low social integration and function. Therefore, the sample will predictably have greater drinking instability and less social rehabilitation. I suggest that different samples of other types of alcoholics at non-NIAAA clinics might well reveal greater stability and social rehabilitation while other samples would show even more instability, poorer outcome and less social rehabilitation.

Second, the sample bias implicitly affects the outcome results. The naive reader might assume that the 19\% successful outcome is rather dismal. In fact, other population samples might give much higher rates of both abstainers and nonproblem drinkers, while other samples might show much poorer outcome rates. Hence, although this is a large national sample, it is not a representative sample. And therefore we should not conclude that the data represent the general outcome rates of treatment. The fact that $42 \%$ had received previous treatment and $32 \%$ had been hospitalized for alcoholism indicates that the sample is heavily loaded with "treatment failures" for whom a good treatment prognosis is already dimmed (10). In essence, this was a high risk" treatment population to begin with. What is surprising is that so many did so well. Finally, it would be valuable to see data on the correlation between previous treatment or hospitalization and drinking outcome status.

Third, this report cannot be considered to be a study of the effectiveness of treatment. Although the NIAAA centers, according to the authors, 
were to provide "comprehensive" and "integrated" treatment, we have no data on that. Mere attendance, time in treatment or treatment offered are very weak indicators of the quality of the treatment programs, which as an intervening variable can significantly influence treatment outcome and long-term status $(11,12)$. Thus, the lack of social rehabilitation may be related either to preentry status or lack of effective treatment intervention, or both. Likewise, the discrepancies in beliefs and self-concept (3, Table 5) may indicate preexistent sets or variations in influence of treatment socialization.

A related treatment issue is the extent to which the treatment program did or did not involve family and significant others in the treatment process, provide active efforts at community and social reintegration and involve the alcoholic patients in follow-up care. Although the data are sparse and equivocal, we need to know whether such treatment variables in the follow-up period may significantly alter the posttreatment instability. On the face of it, it is reasonable to suggest that the 4-year instability indicates the need for programmed aftercare as part of the long-term rehabilitation process.

Finally, I should like to address two interrelated conceptual and definitional issues: the concept of dependence on alcohol and definitions of problem or nonproblem drinking.

First, the authors note that "alcohol dependence is a dimension of preeminent importance, and that it plays an important role in the course of alcoholism" ( $3, p .415)$. Their data are certainly suggestive in this regard, but not particularly clear-cut. The dependence index of 6 items (3, Chart 1$)$ is an odd potpourri. The index is not a conceptually clean set of items, for it contains ideational deficits (loss of control), behavior indicative of high-level consumption (morning drinking, continuous drinking), physical consequences (blackouts, tremors), and an ambiguous item referable either to ideation or consequences (missing meals). We need to construct some good scales to measure both "psychic dependence" and "physical dependence," as differentiated in the World Health Organization description of drug dependence (13). Such scales need to contain items referable to psychological process in the case of psychic dependence; and items referable to tolerance and withdrawal phenomena in the case of physical dependence. What we have in this report is a 6-item index of mixed items, most of which are not direct indices of either kind of dependence, but are rather indirect consequences of presumed dependency-style drinking behavior. Scale indices of both psychic and physical dependence would add more strength to the assessment of degrees of dependence and its relationship to drinking behavior. The authors have made a start in the right direction, but we need a more robust methodology here.

The second issue is the problem of accurately defining drinking behavior. The authors have simply used adverse consequences to define a problem drinker, whereas a nonproblem drinker has no listed adverse 
consequences. Yet their data show that nonproblem drinkers become problem drinkers and vice-versa. In fact, some abstainers become problem drinkers and vice-versa. The authors clearly show and conclude that "the risk of nonproblem drinking varies substantially between different subgroups of alcoholics." It would behoove us to clarify further what psychodynamic and socioenvironmental variables differentiate different subgroups in terms of risk. I suggest that the risk factors are in part related to the prior issue of alcohol dependence-that is, the degree to which an alcoholic maintains substantial psychic dependence on alcohol. Thus a person might reduce the adverse consequences (attenuated drinking behavior) and still have high psychic dependence. A second pattern might be degrees of control over both the psychic dependence and over the adverse behaviors (controlled drinking). This could be total control (abstinence) with still high psychic dependence, or degrees of decreased dependence and increased control (nonproblem drinking). In either case, we have a balance between the impetus to drink (psychic dependence) and the constraining control. It is easy to foresee instability since, if psychic pressure builds up or control goes down, one is going to see a shift in behavior. Such shifts in equilibrium may well be related to both personal psychological characteristics and socioenvironmental variables in the life of the person. Thus "controlled" alcoholics, whether abstinent or nonproblem drinkers, continue to represent degrees of high risk for status instability. Elsewhere $(14,15)$ I have suggested that "normal" drinking outcomes are qualitatively different from either abstinent or controlled drinking outcomes in that psychic dependence has been eliminated. If my logic is plausible here, then the similarity of abstainers and problem drinkers on beliefs and self-concept (Table 5) is predictable, since the total-control abstinent and out-of-control problem drinkers have similar psychic dependence, but vary only on degree of control, whereas the nonproblem drinkers may represent some attenuation of the psychic-dependence variable. These formulations are amenable to empirical assessment, if we can develop appropriate scale measures for these elusive but important intrapsychic variables called psychic dependence and control. It is this sort of problem for which a purely empiricist behavioral methodology may prove inadequate. Hence, despite the problem of measuring psychodynamics, it may be necessary for solving the riddles of instability of alcoholism outcome.

In conclusion, I find this report a yeoman contribution to our understanding of the ongoing ebb and flow of alcoholismic behavior. My criticisms of the report are not of what has been done and reported, but rather a response to where the report should stimulate further research. 


\section{REFERENCES}

1. Polich, J. M., Armor, D. J. and Branker, H. B. The course of alcoholism; four years after treatment. Prepared for the U.S. National Institute on Alcohol Abuse and Alcoholism. Santa Monica, Calif.; Rand Corp.; 1980.

2. Armor, D. J., Polich, J. M. and Stambul, H. B. Alcoholism and treatment. Prepared for the U.S. National Institute on Alcohol Abuse and Alcoholism. Santa Monica, Calif.; Rand Corp.; 1976.

3. Polich, J. M., Armor, D. J. and Bratker, H. B. Patterns of alcoholism over four years. J. Stud. Alcohol 41: 397-416, 1980.

4. Pattison, E. M., Sobell, M. B. and Sobell, L. C. Emerging concepts of alcohol dependence. New York; Springer; 1977.

5. Costello, R. M. Evaluation of post-hospital adjustment; path analysis of causal chains. Eval. \& Hlth Prof. 1: 83-93, 1978.

6. Finnex, J. W. and Moos, R. H. Treatment and outcome for empirical subtypes of alcoholic patients. J. Consult. Clin. Psychol. 47: 25-38, 1979.

7. Pattison, E. M. Differential approaches to multiple problems associated with alcoholism. Contemp. Drug Probl. 9: 265-309, 1978.

8. Pattison, E. M., Coe, R. and Rhodes, R. J. Evaluation of alcoholism treatment; a comparison of three facilities. Archs Gen. Psychiat. 20: 478-488, 1969.

9. Pattison, E. M., Coe, R. and Doerr, H. O. Population variation among alcoholism treatment facilities. Int. J. Addict. 8: 199-229, 1973.

10. Baekeland, F. and Lundwall, L. K. Engaging the alcoholic in treatment and keeping him there. Pp. 161-195. In: Kissin, B. and Beglerter, H., eds. The biology of alcoholism. Vol. 5. Treatment and rehabilitation of the chronic alcoholic. New York; Plenum; 1977.

11. Costello, R. M. Alcoholism treatment and evaluation; in search of methods. II. Collation of two-year follow-up studies. Int. J. Addict. 10: 857-867, 1975.

12. Вromet, E., Moos, R. H. and Bliss, F. The social climate of alcoholism treatment programs. Archs Gen. Psychiat. 33: 910-916, 1976.

13. World Health Organization. Expert Committee on Drugs. Drug dependence; its significance and characteristics. Bull. Wld Hlth Org. 32: 721-733, 1965.

14. Pattison, E. M. Nonabstinent drinking goals in the treatment of alcoholism; a clinical typology. Archs Gen. Psychiat. 33: 923-930, 1976.

15. Pattison, E. M. Nonabstinent drinking goals in the treatment of alcoholics. Pp. 401-455. In: Gibbins, R. J., Israel, Y., Kal.ant, H., Popham, R. E., Schmid, W. and SMART, R. G., eds. Research advances in alcohol and drug problems. Vol. 3. New York; Wiley; 1976. 


\section{Mark B. Sobell and Linda C. Sobell ${ }^{1}$}

The second Rand report $(1,2)$ will most assuredly be subjected to critical scrutiny, a scrutiny matched only by the zealous attention given the initial Rand report (3) and studies reporting nonproblem-drinking outcomes among alcoholics $(4,5)$. While our comments will focus primarily on conceptual issues raised by the most recent Rand report, it should be noted that the over-all methodology of that study was far superior to that of most outcome studies reported to date. Furthermore, greater confidence can be placed in the Rand findings than in most published outcome studies, because the authors went to considerable lengths to validate their data.

Over the past decade it has become increasingly clear that major conceptual changes have been occurring in the alcohol field (6). These changes have been brought about by a wealth of evidence demonstrating that traditional ideas are incongruent with the facts of the disorder. At present it seems that much of the world has already accepted the need, rationale and evidence for these changes. For example, at a conference on "Alcoholism Treatment: Finding New Directions" convened in London, England in April 1979, and attended by persons from a variety of countries, there was a strong consensus that nonabstinent treatment goals were appropriate in the treatment of some alcoholics.

Some particularly critical features of the new knowledge, many of which derive further support from the Rand studies, include $(a)$ a recognition that the population in need of services is very diverse, and that the stereotype of the highly debilitated, chronic, physically dependent alcoholic represents only one subset of the larger treatment population; $(b)$ a recognition that successful recovery from problem drinking is possible for some individuals without their being totally abstinent; and $(c)$ a recognition that recovery from problem drinking is for most a gradual process of improvement rather than an abrupt change in behavior, and, thus, attention should be given to treatment methods aimed at preventing or minimizing the effects of relapses to problem drinking. Other changes are more subtle. For example, in contrast to other terms such as "normal drinking" or "controlled drinking" (each of which yields connotations that go beyond the data), the term "nonproblem drinking" (7) appears to be a much more acceptable way of describing drinking outcomes that do not produce adverse consequences. Use of the label "nonproblem drinking" forces attention to the basic distinction relevant to treatment: it is the consequence or the risk of consequences of drinking that should be the determining feature in evaluating whether any person's drinking is pathological.

\footnotetext{
${ }^{1}$ Clinical Institute, Addiction Research Foundation, 33 Russell St., Toronto, Ontario M5S 2S1, Canada.
} 
Several considerations, important in interpreting the Rand findings, suggest that the Rand data underestimate the potential prevalence and strength of nonproblem-drinking outcomes. First, most, if not all, of the programs evaluated in the Rand study emphasized abstinence as the only acceptable treatment goal. The reported nonproblem-drinking outcomes, therefore, would appear to be quite robust, since they probably occurred despite admonitions by service providers and relatives. Considered in this context, the parity between nonproblem-drinking and abstinent outcomes is remarkable.

Second, the Rand report did not distinguish between patterns of short- and long-term nonproblem drinking. This point is particularly important because it is inappropriate to make comparisons between longterm abstainers and all nonproblem drinkers. For instance, long-term nonproblem drinking could conceivably be an even stronger outcome than long-term abstinence.

A final concern relates to the difference between correlational and causal evidence. The current literature, including the new Rand report $(1,2)$, consistently indicates that less dependent individuals are more likely to attain nonproblem-drinking outcomes than those who have shown more symptoms of dependency. This is not to say that persons who have been physically dependent on alcohol cannot acquire a pattern of nonproblem drinking, but rather that such occurrences are less likely than abstinent outcomes. Unfortunately, at present little is known about what types of persons would fare better in treatment programs explicitly oriented toward nonproblem drinking. Hence, our present knowledge derives mainly from studying the fates of individuals treated using an archaic orientation blatantly incongruent with the known facts about alcohol disorders and patterns of recovery from problem drinking. Thus, a fair evaluation of the efficacy of alternative treatment orientations is lacking. In this regard, since adequate treatments may yet be largely untested, the Rand investigators might be premature in pronouncing problem drinking a highly chronic disorder with unstable patterns of recovery.

We also feel compelled to discuss the manner in which some senior officials of the National Institute on Alcohol Abuse and Alcoholism have attempted to interpret the Rand findings for the news media (8-10). In particular, statements were apparently made to the press suggesting that conclusions in the first Rand report (3) about the viability of nonproblem-drinking outcomes had been reversed in the 4-year outcome studystatements which involved obvious distortions of the facts. Clearly, as is evident from the 4-year report $(1,2)$, the official statements by these national leaders were deceptive, and one can but wonder why they were made. The most frequently voiced justification for such actions is the pretense that one is protecting the best interests of people who suffer from alcohol problems, lest they use the information as a rationalization for resuming or continuing problem drinking. Perhaps the threat of such 
an occurrence is real, although two decades of conflict on this issue show no evidence of a mass return to drinking (11) and this, in and of itself, suggests that the claim is at least a gross exaggeration. Furthermore, we suggest that a more appropriate and responsible way of handling the anticipated side-effects from the presentation of such data on a national level would have been to phrase public statements cautiously (e.g., "The evidence suggests that nonproblem-drinking outcomes are possible for some people, but since we do not yet know for whom they are possible or by what methods they are best attained, any treatment oriented toward that objective should be carefully conducted and not undertaken when the consequences of failure would be great").

Presumably the mission of a federal agency such as NIAAA is to catalyze the provision of services for persons in need of treatment and to further the advancement of knowledge so that more effective treatment can be provided. Public statements by federal officials, such as those made about the Rand reports, suggest that the latter objective is not given much priority by the NIAAA. This state of affairs should be disturbing not only to scientists, but also to all those who have a sincere interest in efforts to reduce alcohol problems. Perhaps the most parsimonious explanation for the misleading statements relates to fears of alarm. ing the highly vocal constituency of traditional service providers who have personal difficulty assimilating the new knowledge that continues to accrue. If such is the case, then it seems likely that the major casualties will continue to be the very persons we all proclaim to help. The time for a major shift in orientation is long overdue, and it is past time for NIAAA to acknowledge that reality. It would be most unfortunate if national leaders were among the last to recognize the changes that are occurring.

\section{REFERENCES}

1. Polich, J. M., Armor, D. J. and Braiker, H. B. Patterns of alcoholism over four years. J. Stud. Alcohol 41: 397-416, 1980.

2. Polich, J. M., Armor, D. J. and Bratker, H. B. The course of alcoholism; four years after treatment. Prepared for the U.S. National Institute on Alcohol Abuse and Alcoholism. Santa Monica, Calif.; Rand Corp.; 1980.

3. Armor, D. J., Polich, J. M. and Stambul, H. B. Alcoholism and treatment. New York; Wiley; 1978.

4. Davies, D. L. Normal drinking in recovered alcohol addicts. Q. J. Stud. Alcohol 23: 94-104, 1962.

5. Sobell, M. B. Alternatives to abstinence; evidence, issues and some proposals. Pp. 177-209. In: Nathan, P. E., Marlatt, G. A. and Loberg, T., eds. Alcoholism; new directions in behavioral research and treatment. New York; Plenum; 1978.

6. Pattison, E. M., Sobell, M. B. and Sobell, L. C. Emerging concepts of alcohol dependence. New York; Springer; 1977.

7. Sobelt, M. B. and Sobell, L. C. Behavioral treatment of alcohol problems; individualized therapy and controlled drinking. New York; Plenum; 1978. 
8. Alcoholics shouldn't drink at all; researchers. The Nashville Banner, 25 January 1980.

9. Controversy over "controlled drinking." Toronto Globe and Mail, 13 February 1980.

10. HoldeN, C. Rand issues final alcoholism report; authors persist in contention that for less severe cases controlled drinking may be feasible. Science 207: 855-856, 1980.

11. Hingson, R., Scotch, N. and Goldman, E. Impact of the "Rand Report" on alcoholics, treatment personnel and Boston residents. J. Stud. Alcohol 38: 2065-2076, 1977.

\section{Martin D. Topper ${ }^{1}$}

The article by Polich et al. (1) has a number of serious problems, although on the whole it represents an effort to open a relatively untouched area of research and should be commended. The authors are correct in stating that there is a "dearth of systematic data about the long-term dynamics of alcoholism" ( $p$. 397). Therefore I find it difficult to be too negative about the findings of their work. However, given the flaws in the basic sampling procedure which I discuss below, I am also inclined to see their conclusions as interesting and provocative hypotheses to be tested in more controlled samples rather than as definitive statements about the long-term dynamics of remission and relapse among "alcoholics."

The major difficulty with this study lies in the failure of the authors to define alcoholism and in their lack of concern for the differences of cultural background in the members of the cohort which they studied. We are all familiar with the copious and often redundant arguments which have been presented in the literature as to what scholars believe alcoholism is or should be. Given this definitional dilemma, one cannot expect these authors to reproduce and solve this argument in a definitive manner. However, we can and should expect that they provide a statement of how they defined alcoholism and the reasons for which they chose a specific definition. Instead, they chose to study patients who were admitted for the treatment of alcoholism at a number of treatment centers funded by NIAAA. Therefore we are left with a sample of patients who fit the various criteria of the various NIAAA treatment centers.

1 P.O. Box 5, Tuba City, Arizona 86045. 
Anyone who works with patients knows that the use of patients in a study has a number of limitations. First, there are the limitations imposed by the definition of alcoholism which the treatment center uses. Treatment centers, no matter how broadly conceived, must screen admissions. What were the criteria for this screening? Were they the same at all NIAAA centers? Do they fit an adequately defined research criteria for alcoholism? The lack of answers to these questions is disturbing. A second, more serious problem comes from the fact that when one deals with patients, one only becomes involved with those alcoholics who somehow find their way into the treatment system. What about alcoholics who do not receive treatment? Is the long-term course of their alcoholism the same as those who do receive treatment? What the authors have presented is a profile of patients who happened to be treated by the NIAAA treatment centers. It is not a sample of alcoholics in general.

In addition to the above, I have some doubts about the use of a population of drinkers in Seattle, Washington, as a control for a study of drinkers throughout the United States and about the "psychiatric" measurements made by the authors. However, to elaborate on hese points would only further delay the presentation of the major point of this review. That point, stated simply, is that the sample used was too biased to represent what the authors purport it represents. This is not a study of the 4-year treatment outcomes of alcoholics in the United States; it is a study of the 4-year treatment outcomes of some of the patients of the NIAAA treatment centers.

Given these problems, it is not possible to accept the findings of this study as being firm and representative conclusions about the nature of the outcomes of treating alcoholics. However, as flawed as it is, the study does present some interesting conclusions which might form hypotheses for more controlled studies. The area which the authors have opened is important and may help produce a much needed union between our colleagues in the fields of alcohol research and treatment.

\section{REFERENCE}

1. Polich, J. M., Аrmor, D. J. and Braiker, H. Patterns of alcoholism over four years. J. Stud. Alcohol 41: 397-416, 1980. 


\section{A Response}

\section{J. Michael Polich, David J. Armor and Harriet B. Braiker ${ }^{1}$}

In general, we agree with the substantive points made in the above comments. Most observers recognize that alcoholism is indeed a chronic condition with a high risk of relapse; that both abstinence and nonproblem drinking outcomes represent forms of remission for some alcoholics; and that relapse is a complex phenomenon governed by the alcoholic's drinking history and social environment, rather than simply by his decision to drink or not to drink.

A number of reviewers have raised important questions that deserve further discussion and suggest avenues for future research. We will respond briefly to three such questions.

\section{The Study Group versus Other Alcoholic Populations}

Several reviewers wondered whether our study sample, randomly drawn from patients admitted to publicly funded alcoholism treatment centers, might be atypical or "biased" compared with other groups of alcoholics. Pattison points out that some alcoholics (e.g., prisoners) might have much lower remission rates than our sample, whereas more stable populations might have higher rates. Topper suggests that unknown features of our treatment centers (e.g., criteria for admission) might make our sample unique.

We agree with Pattison that different treatment populations can be expected to have sharply different remission rates if they vary in prognostic background characteristics. Our full report (1) included multivariate models relevant to this point, relating remission to patient and treatment characteristics (Table 6.18). Based on these data, we can estimate that among a patient group with the most favorable prognosis (no dependence symptoms and no previous treatment), the remission rate would range between 60 and $75 \%$, while among a group with the least favorable prognosis, the rate would range between 26 and $41 \%$. Patient background should make a large difference in outcome expectations.

However, these variations do not indicate that our sample is unrepresentative of the general treated population of alcoholics. In fact, data

1 The Rand Corporation, Santa Monica, California 90406. 
shown in our report indicate otherwise (1, Table 2.1). We compared the 4-year study sample with a sample of patients admitted to facilities randomly drawn from all recognized alcoholism treatment institutions in the United States. The two patient groups showed only slight differences on important prognostic factors. These results suggest that, on the most important characteristics for which data are available, the subjects in this study are similar to the population of all alcoholics admitted to formal treatment institutions in the U.S.

The question of untreated alcoholics is an entirely different matter. As several reviewers pointed out, untreated alcoholics may differ in numerous ways from those who enter treatment. We agree wholeheartedly that present knowledge about untreated alcoholics is inadequate. There are many unanswered questions about the rate of natural remission, the processes by which alcoholism develops and the factors that lead people to enter treatment. These questions deserve much more attention in future research.

\section{Treatment}

Several reviewers addressed our findings about treatment. Since these results were discussed in the full report (1) but not in the shorter article (2), we will summarize them here. We conducted several analyses to examine the relationship between treatment and remission at 4 years, adjusting for the patient's initial dependence level, previous alcoholism treatment, social stability, socioeconomic status, age and race. Although the available treatment data were not detailed, we did have information about the important variables of treatment setting (e.g., inpatient versus outpatient) and treatment amounts (e.g., number of inpatient days or outpatient visits). After controlling for patient background characteristics, we found a modest positive association between remission and higher amounts of treatment, although it was confined to outpatient settings only. Over-all, no significant difference in remission rates was found for inpatient versus outpatient settings. Since the study was not based on randomized assignments to treatment modalities, we cautioned that the findings were correlational in nature and could be subject to selection effects. We did conclude, however, that "the cost-effectiveness of inpatient treatments is very much an open question" $(1, p .182)$.

As many reviewers noted, our report emphasized that the nature of the study design precludes definitive conclusions about treatment policies. The lack of an untreated control group, the absence of randomized assignment and the limited number of treatment process variables hamper interpretation of the treatment differences. For example, even though a remission rate of $46 \%$ may seem relatively low to some observers, it may be high compared with remission rates for untreated alcoholics who never make contact with a treatment facility. Moreover, the higher remission rate for high amounts of outpatient care could be due to selfselection effects rather than to the amount of treatment per se (e.g., 
patients who succeed in treatment might return for more outpatient visits). Even the failure to find differences between inpatient and outpatient modalities could be explained by the "quality" of treatment, or perhaps by a complex self-sorting process that might mask underlying effects of different treatments.

The fact is that rigorous studies of treatment effects are rare in the alcoholism field. Randomization of patients to treatment groups is difficult, and, as Moos and Finney point out, serious problems are encountered in trying to study an "untreated" control group. Among other reasons are the availability of funds, cooperation of treatment institutions, and, perhaps, the energies of researchers in the face of such a difficult undertaking. The challenge to the treatment field is to overcome these obstacles and to initiate programs that foster experimental research designs. Until such research is forthcoming, policy makers have no choice but to rely on the existing evidence.

\section{The Definition of Alcoholism}

A fundamental point is raised by Topper, who notes that the study did not utilize a specific definition of alcoholism. By implication, the fact that we did not impose a restrictive definition could mean that some "nonalcoholics" were included in the sample. This is also a point of criticism raised by others (3), who maintain that those members of our sample who returned to nonproblem drinking may not have been alcoholics to begin with. These possibilities raise important issues.

One point is perhaps obvious: an alcoholic cannot be defined simply as a person who can never achieve nonproblem drinking. That definition would not only be circular, but would also require a clinician to foresee a patient's entire future in order to make a diagnosis. Clearly, such a definition has little utility either for science or for treatment practice.

Rather than adopt such an approach, we used operational measures reflecting criteria that are widely accepted as indicators of alcoholism: level of alcohol dependence $(4,5)$ and adverse consequences or "harm due to drinking" $(6,7)$. Analysis in the report clearly reveals that this sample was highly impaired on these variables at admission to treatment. Furthermore, sensitivity analysis of our data shows that excluding the small number of subjects who did not meet such criteria would not significantly affect the proportion of abstainers or nonproblem drinkers at 4 years (1, Table 3.28).

Since no clear consensus exists on the definition of alcoholism, we felt it unwise to exclude subjects from our sample using any single criterion. Indeed, our data suggest that a single definition of alcoholism is not appropriate. We found that an alcoholic's chance of relapse depends on multiple factors, thereby differentiating diverse types of alcoholics. The multivariate model of relapse $(2$, Table 7$)$ revealed complex patterns of interaction among initial level of alcohol dependence, social environment and posttreatment drinking behavior. As noted by Ogborne, 
such results help us recognize that alcoholism is a heterogeneous phenomenon. Rather than continuing to search for a simple definition of this complex phenomenon, we would be better advised to seek further understanding of the fundamental variables that distinguish among the different types of alcoholics.

\section{REFERENCES}

1. Polich, J. M., Armor, D. J. and Braiker, H. B. The course of alcoholism; four years after treatment. Prepared for the U.S. National Institute on Alcohol Abuse and Alcoholism. Santa Monica, Calif.; Rand Corp.; 1980.

2. Polich, J. M., Armor, D. J. and Braiker, H. B. Patterns of alcoholism over four years. J. Stud. Alcohol 41: 397-416, 1980.

3. Rand issues final alcoholism report. Science 207: 855-856, 1980.

4. Edwards, G., Gross, M. M., Keller, M., Moser, J. and Room, R. Alcoholrelated disabilities. (WHO Publ. No. 32) Geneva; World Health Organization; 1977.

5. Edwards, G. and Gross, M. M. Alcohol dependence; provisional description of a clinical syndrome. Br. Med. J. 1: 1058-1061, 1976.

6. Keller, M. The definition of alcoholism and the estimation of its prevalence. Pp. 310-329. In: Pittman, D. J. and Snyder, C. R., eds. Society, culture, and drinking patterns. New York; Wiley; 1962.

7. Davies, D. L. Definitional issues in alcoholism. Pp. 53-73. In: Tarter, R. E. and Sugerman, A. A., eds. Alcoholism; interdisciplinary approaches to an enduring problem. Reading, Mass.; Addison-Wesley; 1976. 